Disponível em:

http://editora.unoesc.edu.br/index.php/race

Race, Joaçaba, v. 15, n. 2, p. 505-530, maio/ago. 2016

\title{
IMPACTO DOS ROYALTIES DO PETRÓLEO NO ÍNDICE DE EDUCAÇÃO BÁSICA: ANÁLISE DO CASO DOS MUNICÍPIOS CAPIXABAS
}

Impact of oil royalties in basic education index: analysis of the capixaba municipalities case

Antonio Lopo Martinez

E-mail: lopo@fucape.br

Doutor em Controladoria e Contabilidade pela Universidade de São Paulo; Doutor em Administração pela Fundação Getúlio Vargas; Professor Associado e Pesquisador

da Fundação Instituto Capixaba de Pesquisa em Contabilidade, Economia e Finanças. Endereço para contato: Avenida Fernando Ferrari, 1358, Boa Vista, 29075-505, Vitória, Espírito Santo, Brasil.

Sergio dos Santos Reis

E-mail: sergiodosreis@hotmail.com

Mestre em Ciências Contábeis pela Fundação Instituto Capixaba de Pesquisas em Contabilidade, Economia e Finanças; Doutorando em Economia pela Universidade de La Matanza (Buenos Aires); Professor da Universidade Vale do Rio Doce.

Artigo recebido em 06 de novembro de 2015. Aceito em 21 de dezembro de 2015. 


\section{Resumo}

Neste trabalho analisou-se o impacto dos royalties do petróleo e gás no índice de desenvolvimento da educação básica (IDEB) nos municípios do Espírito Santo (Brasil) entre os anos 2006 e 2013. O objetivo foi identificar se há uma associação positiva entre o IDEB e as receitas provenientes de royalties de petróleo transferida pelo Governo Federal para os municípios. No trabalho utilizaram-se dados coletados e compilados a partir de documentos obtidos na Agência Nacional de Petróleo (ANP) e no Instituto Nacional de Estudos e Pesquisa (INEP). Utilizando regressões em painel para o IDEB, na sua categoria anos iniciais e anos finais, investigaram-se 67 municípios capixabas. Os resultados encontrados apontam para uma associação entre a avaliação no IDEB e os royalties do petróleo e gás. Conclui-se que há uma relação positiva significativa entre o aumento de receitas provenientes dos royalties do petróleo e gás e o crescimento do IDEB no período e amostra analisados. Desse modo, há evidências que a nota do IDEB cresce à medida que aumentam as receitas provenientes de royalties do petróleo e gás em determinado município.

Palavras-chave: Royalties do petróleo e gás. IDEB. Investimentos.

\section{Abstract}

In this paper we analyzed the impact of oil and gas royalties in the Basic Education Development Index (IDEB) in the municipalities of Espírito Santo (Brazil) between 2006 and 2013. The aim was to identify whether there is a positive association between the IDEB and revenues from oil royalties transferred by the federal government to the municipalities. At work they used data collected and compiled from documents obtained from the National Petroleum Agency (ANP) and the National Institute of Studies and Research (INEP). Using regressions panel to the IDEB in its category early years and later years, they investigated 67 capixabas municipalities. The results point to an association between the assessment in IDEB and oil and gas royalties. It is concluded that there is a significant positive relationship between increased revenues from oil and gas royalties and growth of IDEB in the period and analyzed sample. Thus, there is evidence that the IDEB Note grows as increase revenue from oil and gas royalties in a given municipality. Keywords: Royalties from oil and gas. IDEB. Investments.

\section{INTRODUÇÃO}

As descobertas de petróleo no chamado pré-sal têm aguçado o interesse da sociedade no que se refere aos recursos gerados decorrentes da exploração e utilização de petróleo e gás. Muitas perguntas podem ser feitas pelo cidadão, entre as quais se destacam: os royalties do petróleo e gás serão utilizados de qual forma? Qual o destino dessas importâncias no orçamento dos entes públicos? As receitas têm sido 
utilizadas em melhorias para a sociedade ou aprimoramento da máquina pública? De modo geral, predomina a percepção cética de que a utilização desses recursos não tem se refletido em resultados concretos. Neste trabalho almeja-se explorar e procurar responder, parcialmente, a essas questões instigantes.

A pesquisa desenvolvida navega na busca dessas questões, analisando a partir da compilação de dados contábeis do orçamento dos municípios beneficiados pelo repasse de royalties do petróleo e gás no Estado do Espírito Santo de 2006 a 2013. Houve algum benefício para a sociedade, em particular referente à educação básica?

A análise tem como ponto de partida as informações de transferências dos royalties do petróleo para os municípios do Espírito Santo, e almeja-se verificar se existe uma correlação entre a variação do índice de desenvolvimento da educação básica (IDEB) e a receita decorrente da compensação pela exploração dos campos de produção de petróleo. Acrescente-se, por pertinente, que o estudo apreciou a associação dos royalties com o IDEB nos seus dois segmentos de análise, seja anos iniciais ( $4^{\mathrm{a}}$ série ou $5^{\circ}$ ano) seja anos finais ( $8^{\mathrm{a}}$ série ou $9^{\circ}$ ano), permitindo uma investigação mais detalhada dos seus efeitos na educação básica.

O IDEB foi criado, em 2007, para oferecer métricas que mensurem a eficiência de nosso sistema educacional, tendo por base referências internacionais de qualidade. O índice é calculado bienalmente, considerando-se a Prova Brasil e o desempenho dos alunos no Sistema Nacional de Avaliação da Educação Básica (SAEB). A partir dessas notas compostas, chega-se ao cálculo do IDEB, analisando-se taxa de rendimento escolar, evasão e aprovação.

Para este estudo, os dados analisados do IDEB referem-se a um período de oito anos, e o estudo focalizou 78 municípios do Estado do Espírito Santo. Dada a relevância dos royalties no contexto do Espírito Santo, e sendo um dos Estados que tem tido afortunado com uma parcela significativa dos royalties, presume-se, por hipótese, que este oferece uma excelente área de pesquisa para verificar os efeitos em indicadores sociais, diga-se, neste caso, o IDEB, do recebimento de royalties por determinando município.

\section{REVISÃO DA LITERATURA}

\subsection{ROYALTIES NO BRASIL}

A instituição da cobrança dos royalties do petróleo e gás no Brasil não é tão recente, suas primeiras legislações regulamentadoras ocorreram a partir dos anos 1950, 
quando foi instituída a Lei n. 2004, datada de 03 de outubro de 1953, criada a Petrobrás e instituído o monopólio do petróleo, definindo alíquota para produção em terra.

Em 1997 foi revogada a Lei n. 2004/53 por meio da nova Lei n. 9.478/97, mantendo a Petrobrás, alterando, assim, a alíquota básica e os critérios de arrecadação e distribuição aos entes da federação, bem como na aplicação desses recursos ora arrecadados das empresas públicas ou privadas responsáveis pela exploração petrolífera. A chamada Lei do Petróleo criou a Agência Nacional do Petróleo (ANP), que é uma autarquia federal vinculada à União, com papel bem definido na regulação na indústria do petróleo. Todos os cálculos e fiscalização do pagamento de royalties do petróleo e gás natural é de competência da ANP.

Descreve Ribeiro (2008): “A legislação chegou a prever uma obrigatoriedade de investimentos em infraestrutura [...]” Gonçalves et al. (2010, p. 4) corroboram que: "As discussões a respeito da cobrança dos royalties tomam forma quando ela é utilizada para cumprimento das funções do Estado.” Em se tratando de royalties de mineração, Silva e Silveira (2012), em seu trabalho, analisam o repasse de royalties do minério para o desenvolvimento socioeconômico dos municípios de Minas Gerais que possuem extração de minério; entre as variáveis, os autores analisam o IDEB dos anos iniciais e finais e afirmam que: "Para o IDEB $4^{\text {a }}$ e $8^{\text {a }}$ série, os municípios apresentam médias um pouco próximo [...]” (SILVA; SILVEIRA, 2012, p. 14), ou seja, o IDEB dos anos iniciais e finais apresenta valores médios baixos.

As receitas públicas são fontes de recursos dos entes da Federação, que são utilizadas para manutenção das funções do Estado; as despesas geradas dependem diretamente de recursos ora cobrados, ora captados por meio de financiamentos diversos, bem como de parcerias que gerarão recursos aos cofres públicos. As receitas públicas orçamentárias podem ser correntes ou de capital, conforme Manual da Receita Nacional Aplicado à União, Estados, Distrito Federal e Municípios.

As receitas são classificadas em receitas correntes ou receitas de capital por força da Lei n. 4.320/64; elas são provenientes de várias fontes de renda, como tributos, contratos de empréstimos, de transferências, correntes constitucionais e outras formas. As receitas de royalties do petróleo são provenientes de compensações financeiras (MACHADO JÚNIOR; REIS, 2002).

Gonçalves et al. (2010, p. 3) afirmam: “A cobrança do royalty é uma das formas mais antigas de pagamento de direitos. A palavra royalty vem do inglês royal, que significa realeza ou relativa ao rei.”

Ribeiro (2008 apud LEAL; SERRA, 2003, p. 64) define royalties como: “[...] o fluxo de pagamentos aos proprietários de um ativo não renovável (material ou ima- 
terial) que o cede para ser explorado, usado ou comercializado por outras empresas ou indivíduos.”

A remuneração dos royalties ao Estado é regulamentada pela Lei n. 9.478/97 e por normas adicionais provenientes da distribuição e participação de cada ente da Federação nas receitas provenientes do petróleo e gás.

O contrato que concede a exploração deverá passar por processo de licitação após observada a Lei n. 9.478/97. No contrato deve conter bônus de assinatura, royalties, participação especial e pagamento pela ocupação ou retenção de área; a participação especial e o bônus de assinatura não são participações governamentais obrigatórias, embora no Brasil exista tal prática.

Remuneração por bônus de assinatura é o valor pago pelas empresas que vencem o processo licitatório da área de concessão; conforme a legislação brasileira, o edital definirá o percentual de bônus mínimo a ser pago correspondente ao pagamento ofertado para obter a licença de exploração. O bônus de assinatura, conforme sugerido pelo próprio nome, deverá ser pago na assinatura do contrato de concessão em parcela única. O valor pago referente a bônus de assinatura é destinado à ANP, observando-se a legislação (Lei n. 9.487/97) que define a parcela de participações governamentais (BRASIL, 1997).

A remuneração por participação adicional em campos de produção de grandes volumes ou com grande rentabilidade, o edital definirá, e, consequentemente, deverá constar no contrato a participação especial, ou seja, o percentual definido sobre a receita líquida da produção, conforme previsão da legislação vigente e os tributos (BRASIL, 1997). A remuneração proveniente da participação especial tem a seguinte proporção, conforme a Lei n. 9.487/97: 40\% ao Ministério de Minas e Energia, 10\% ao Ministério do Meio Ambiente, dos Recursos Hídricos e da Amazônia Legal, 40\% para o Estado (local da produção em terra), ou limites com a plataforma continental onde se realizar a produção; 10\% para o Município (local da produção em terra), ou limites com a plataforma continental onde se realizar a produção (BRASIL, 1997).

A remuneração pela ocupação e retenção da área é o pagamento previsto no art. 50 da Lei n. 9.478/97, que é feita pela ocupação e retenção de área no Brasil. Esse pagamento também é comum, por exemplo, em regimes fiscais de outros países produtores de petróleo, conhecido como rentalfree. O contrato de concessão obedece sempre ao edital e prevê esse pagamento, que será anual pela ocupação e retenção da área; sua métrica para o cálculo dessa remuneração é o $\mathrm{km}^{2}$ (quilômetro quadrado) ou a fração da superfície do bloco concedido. 
Deverá ser previsto no contrato da concessão de bloco em terra cláusula que define o pagamento em moeda corrente aos donos de terra, de um percentual variável entre 0,5\% e 1\% da produção de petróleo ou gás natural (BRASIL, 1997).

\subsection{GASTOS PÚBLICOS}

Em se tratando de gastos públicos, Sant’anna (2006) afirma que estes são: “[...] as despesas direcionadas para as áreas de educação, saúde, seguridade e assistência social, emprego, saneamento e habitação.”

Arcar com despesas em educação é função do Governo, compete a ele investir em educação. Sant’anna (2006) afirma que as despesas com educação são consideradas gasto público social, e tais gastos são necessários para dispor de serviços e bens para a sociedade.

Silva e Silveira (2012, p. 5) afirmam que: “Os gastos públicos devem estar direcionados para combater as causas básicas dos problemas sociais e não apenas para ‘disfarçar' as questões mais profundas destes.” Nessa linha de estudo, definindo que a educação é função do Estado, Silva et al. (2013, p. 5) afirmam: “A realização dessas funções econômicas possibilita que o Estado busque o desenvolvimento econômico e, assim, consiga cumprir as expectativas e necessidades da sociedade.”

Uma das funções do Estado é alocar nos gastos públicos sociais despesas com educação e identificar as necessidades para alcançar resultados nos índices do Governo (GIAMBIAGI; ALÉM, 2008).

Conforme a tradicional classificação citada por Giambiagi e Além (2008), nos Estados modernos, a política de gastos, ou política fiscal do governo, tem três funções: distributiva, estabilizadora e alocativa.

A função alocativa diz respeito ao fornecimento de bens públicos, que são aqueles cuja utilização por um indivíduo não implica a indisponibilidade para os outros indivíduos (GIAMBIAGI; ALÉM, 2008). Exemplos: escolas, iluminação pública, policiamento, praças públicas, etc. É a função do governo por meio da qual se presta serviço público igual para todos, não restringindo a classe social que terá acesso ao direito, pois possui função de disponibilidade coletiva; todos os serviços são colocados à disposição do indivíduo.

A função distributiva tem como objetivo distribuir a renda à população de modo equilibrado, minimizando as diferenças que o mercado provoca na distribuição; é a mais complexa das funções classificadas por Giambiagi e Além (2008), e pode ser exemplificada por transferências de renda, impostos diretos para financiar serviços 
públicos (moradia popular, etc.) e subsídios aos produtos consumidos pelas classes pobres, como é o caso do imposto zero para itens da cesta básica.

A função estabilizadora tem por objetivo alcançar um elevado nível de emprego, uma estabilidade no nível de preços, equilíbrio no balanço de pagamentos e uma taxa de crescimento econômico. A principal utilização da função nos gastos públicos são as políticas anticíclicas do Governo. Os gastos públicos e os investimentos aumentam no ciclo de recessão econômica para incentivar a iniciativa privada a reverter tal situação da economia. Funciona como uma balizadora dos efeitos negativos em época de crise financeira.

Silva et al. (2013) definem que a função alocativa do Estado está ligada a serviços de educação, o poder público municipal é responsável por gastos públicos para alcançar a qualidade de ensino, e a métrica atual é o IDEB.

Para o Ministério da Fazenda (2008, p. 13), as despesas públicas são:

[...] é a aplicação de recursos pecuniários em forma de gastos e em forma de mutação patrimonial, com o fim de realizar as finalidades do estado e, em sua acepção econômica, é o gasto ou não de dinheiro para efetuar serviços tendentes àquelas finalidades; compromisso de gasto dos recursos públicos [...]

As despesas públicas podem ser orçamentárias ou extra-orçamentárias, mas se deve obedecer a classificação orçamentária definida pela Lei n. 4.320/64.

Embora a legislação defina que as despesas deverão ser correntes e de capital, Sant'anna (2011) conceitua o gasto púbico como “[...] todo aquele apresentado como despesas.”

As despesas são classificadas segundo a Portaria Interministerial n. 163/2001, categoria econômica, e as funções e subfunções da despesa pública, conforme Portaria n. 42/1999 do Ministério do Planejamento, Orçamentário e Gestão. Uma das funções das despesas públicas descritas na Portaria n. 42/99 é a função Educação (Código 12) e cujas subfunções são: 361 - Ensino Fundamental, 362 - Ensino Médio, 363 - Ensino Profissional, 364 - Ensino Superior, 365 - Educação Infantil, 366 - Educação de Jovens e 367 - Educação Especial (BRASIL, 1999).

As despesas executadas são necessárias para atingir objetivos e metas, conforme é a função do Governo, seja ela alocativa, distributiva ou estabilizadora. A despesa com educação é alocativa, e os gastos em outras áreas impactam na educação, como na construção de escolas, de quadras poliesportivas e de estradas em razão da escola pública. 


\section{3 ÍNDICE DE DESENVOLVIMENTO DA EDUCACAO BÁSICA NO BRASIL}

O Índice De Desenvolvimento Da Educação Básica (IDEB) foi criado em 2007 para medir a educação brasileira. Ele é calculado bienalmente, conforme padrões internacionais, baseado nas notas da Prova Brasil e no desempenho dos alunos no Sistema Nacional de Avaliação da Educação Básica (SAEB).

O IDEB faz parte do Plano de Desenvolvimento da Educação (PDE) do Governo Federal e inclui todos os Estados da Federação e Municípios do Brasil, e a análise é feita no Ensino Fundamental (anos iniciais e finais) e no Ensino Médio.

O Brasil estabeleceu meta até 2022, conforme o PDE, para que o IDEB seja 6,0 - média comparável aos padrões internacionais de educação nos países chamados de desenvolvidos (INSTITUTO NACIONAL DE ESTUDOS E PESQUISAS ANÍSIO TEIXEIRA, 2014).

Segundo dados no Portal do MEC, em sua nota técnica, define-se que o IDEB é:

[...] resultado do produto entre o desempenho e rendimento escolar (ou o inverso do tempo médio de conclusão de uma série) então ele pode ser interpretado da seguinte maneira: para uma escola A cuja média padronizada da Prova Brasil, 4 a série, é 5,0 e o tempo médio de conclusão de cada série é de 2 anos, a rede/ escola terá o Ideb igual a 5,0 multiplicado por 1/2, ou seja, Ideb = 2,5. Já uma escola B com média padronizada da Prova Brasil, $4^{\mathrm{a}}$ série, igual a 5,0 e tempo médio para conclusão igual a 1 ano, terá Ideb = 5,0. (INSTITUTO NACIONAL DE ESTUDOS E PESQUISAS ANÍSIO TEIXEIRA, 2014).

Costa (2010, p. 17) conclui que "O IDEB é o 'termômetro da qualidade' da educação básica brasileira e sua proposta, como monitoramento do objetivo da qualidade dos sistemas de ensino, a partir da combinação entre fluxo e aprendizagem escolar, devem se tornar públicas”, e o Estado é responsável pela aferição pelos meios de avaliação estabelecidos pelo MEC.

No que se refere à responsabilidade e à qualidade, Lopes, Passador e Passador (2014) afirmam que o Estado tem a responsabilidade de oferecer boas condições educacionais para cumprir o papel de cidadania esperado por todos os brasileiros, e a educação ocupa um papel de destaque no exercício da cidadania.

No que se refere à aplicação nos gastos públicos para alcançar a qualidade no ensino, são necessárias previsões orçamentárias, como receitas correntes e receitas 
de capital na Educação, as quais interferem diretamente nos resultados do IDEB tanto para anos iniciais quanto para os anos finais do Ensino Fundamental. Conforme Crozatti e Almeida (2012, p. 13):

[...] a qualidade do gasto público é dada pela relação entre o desempenho no IDEB e gasto orçamentário na sub função educação fundamental. Dessa forma, municípios que apresentam baixo gasto médio por aluno no ensino fundamental, porém apresentam resultados médios no IDEB, podem se destacar frente a outros que investem altos valores e apresentam resultados bons ou ótimos.

A nova lei aprovada no Congresso Nacional, a Lei dos Royalties (n. 12.858/2013), define que as receitas provenientes do petróleo e gás extraído do pré-sal tenham investimentos diretamente na educação e saúde dos entes da Federação, seja o recurso extraído dos municípios beneficiados seja de todos os municípios que tiverem recurso de royalties do petróleo e gás.

A cada ano que passa, os resultados têm atingido índices importantes para a educação; os resultados de 2013 demonstraram uma melhora na média nacional no Ensino Fundamental, a qual, de 5,0 em 2011, mudou para 5,2 em 2013 (INSTITUTO NACIONAL DE ESTUDOS E PESQUISAS ANÍSIO TEIXEIRA, 2014).

Assim, o índice de desenvolvimento da educação básica no Brasil tem alcançado resultados relevantes para o atendimento das metas internacionais e, concomitantemente, proporciona a análise da qualidade da educação no Brasil.

\section{METODOLOGIA}

A base de dados da pesquisa abrangeu os 78 municípios do Estado do Espírito Santo com nota média do IDEB para as escolas, totalizando 624 amostras. Foram reduzidas as observações para análise do IDEB anos iniciais ( $4^{\mathrm{a}}$ série ou $5^{\circ}$ ano) e do IDEB anos finais ( $8^{\mathrm{a}}$ série ou $9^{\circ}$ ano). Alguns municípios não tiveram avaliações do IDEB, consequentemente, não tiveram metas do IDEB cumpridas conforme métrica do Governo.

Este trabalho é uma pesquisa quantitativa, na qual, com dados secundários, analisa-se a relação positiva entre o Índice de Desenvolvimento da Educação Básica (IDEB) dos anos iniciais e finais e as receitas provenientes de royalties de petróleo e gás, transferidas pelo Governo Federal para os municípios abrangidos pela região de exploração. Os dados foram coletados no site da ANP e no Instituto Nacional de Estudos e de Pesquisas Educacionais (INEP). 
Os dados são estimados por meio de regressão múltipla para identificar a relação entre a variável dependente IDEB e as variáveis independentes.

A coleta dos dados ocorreu em 78 municípios, e a base completa comporta 624 amostras; foram efetuados os devidos cortes por falta de informações completas.

Dessa forma, utilizaram-se os índices do IDEB, de forma a avaliar os royalties do petróleo e gás, analisando as relações existentes entre as variáveis, se estas possuem poder preditivo quanto ao valor da variável dependente (IDEB) em análise.

De acordo com Sant'anna (2006), o método de avaliação mais adequado é o chamado dados em painel, por se tratar de uma pesquisa feita com municípios diferentes e por vários anos (série temporal) no teste conforme descrito como "conjunto de longituginal” (SANT’ANNA, 2006 apud PINDICK; RUBINFELD, 2004, p. 288).

Utilizou-se o método dados em painel em razão de amostra ser constituída por municípios ao longo de um período de tempo, sendo uma ferramenta estatística para análise e tratamento dos dados, sugerindo a existência de características diferenciadoras entre os municípios da amostragem, portanto, o painel ficou i=1,...,78 e t=1,..,8.

Os dados do IDEB são publicados no site do INEP a cada dois anos; foram extraídas as séries de 2005 a 2013 para o IDEB, porém, o ano 2005 não foi comparativo para efeito de metas a serem atingidas, sendo excluído o ano e mantido o IDEB do ano anterior para a devida variável de controle.

As variáveis a serem analisadas neste estudo estão descritas a seguir:

Quadro 1 - Variáveis transformadas

\begin{tabular}{|c|c|}
\hline Variável & Descrição \\
\hline IdebIni & $\begin{array}{l}\text { Nota do município nos anos iniciais (4 } 4^{\text {a }} \text { série ou } 5^{\circ} \text { ano) da Educação Básica de } \\
2006 \text { a 2013, variável dependente. Extraído do INEP/MEC. }\end{array}$ \\
\hline InRoyalPerCapta $_{t-1}$ & $\begin{array}{l}\text { Logaritmo dos Royalties per capita dos municípios com defasagem de } 1 \text { ano } \\
\text { (t-1), variável independente (explicativa), transforma. }\end{array}$ \\
\hline IdebIni_A & $\begin{array}{l}\text { Nota do IDEB anterior nos anos iniciais ( } 4^{\text {a }} \text { série ou } 5^{\circ} \text { ano) referente ao municí- } \\
\text { pio, variável de controle. }\end{array}$ \\
\hline IdebIni_M & $\begin{array}{l}\text { Meta obtida é maior ou igual à meta projetada pelo Governo ( } 0=\text { Não e } 1=S i m) \text {, } \\
\text { variável de controle. }\end{array}$ \\
\hline IdebFin & $\begin{array}{l}\text { Nota do município nos anos finais (8ª série ou 9ªno) da Educação Básica de } \\
2006 \text { a 2013, variável dependente. }\end{array}$ \\
\hline IdebFin_A & $\begin{array}{l}\text { Nota do IDEB anterior nos anos finais( } 8^{\mathrm{a}} \text { série ou } 9^{\circ} \text { ano) referente ao municí- } \\
\text { pio, variável de controle. }\end{array}$ \\
\hline IdebFin_M & $\begin{array}{l}\text { Meta obtida é maior ou igual à meta projetada pelo Governo ( } 0=\text { Não e } 1=\text { Sim), } \\
\text { variável de controle. }\end{array}$ \\
\hline
\end{tabular}

Fonte: os autores. 
Desse modo, para analisar o IDEB dos anos iniciais ( $4^{\mathrm{a}}$ série ou $5^{\circ}$ ano) e anos finais ( $8^{\mathrm{a}}$ série ou $9^{\circ}$ ano), o seguinte modelo é proposto:

a) Modelo para os anos iniciais:

IdebIni $_{i}=\hat{a}_{0}+\hat{a}_{1} \mathrm{~h}$ Royalpercapta $\mathrm{t}_{\mathrm{t}-1}+\hat{a}_{2}$ IdebIni $_{-} A+\hat{a}_{3}$ IdebIni $_{-} M+\stackrel{\circ}{a}_{i}$

b) Modelos para os anos finais:

IdebFin $_{i}=\hat{a}_{0}+\hat{a}_{1} \mathrm{~h}$ Royalpercapta $\mathrm{t}_{\mathrm{t}-1}+\hat{a}_{2}$ IdebFin_A $_{-}+\hat{a}_{3}$ IdebFin_ $_{-} M+\stackrel{\circ}{a}_{i}$

\section{ANÁLISE DOS RESULTADOS}

Nesta seção são apresentados os resultados provenientes das Análises de Regressão Múltipla aplicadas para avaliar a variação no IDEB anos iniciais ( $4^{\mathrm{a}}$ série ou $5^{\circ}$ ano) e anos finais ( $8^{\text {a }}$ série ou $9^{\circ}$ ano), correspondentes aos índices de educação básica dos municípios do Estado do Espírito Santo. A variável IdebIni identifica os anos iniciais, e a variável IdebFin identifica os anos finais no ensino fundamental; o índice do IDEB é calculado bienalmente com base em informações de aprovação, reprovação e evasão.

Analisaram-se os dados da aplicação dos recursos dos royalties arrecadados em um determinado ano e foram apontados resultados nos anos posteriores, exercendo influência maior que as demais informações dentro de um mesmo ano.

Uma preocupação em relação aos dados refere-se à dispersão da variável explicativa RoyalPerCapta, por se tratarem de dados financeiros, os quais foram logarimatizados. O fato de a variável IDEB variar menos do que as variáveis explicativas pode implicar problemas de perturbações nos modelos referentes aos erros ou resíduos. Transformações matemáticas nas variáveis podem reduzir os ruídos dos modelos e melhorar as estimativas acerca das suposições dos resíduos ou erros aleatórios. De acordo com Malhotra (2001), Levine, Berenson e Stephen (2008) e Hair Júnior et al. (2009), transformações como tomar o logaritmo ou as raízes quadradas das variáveis dependentes e/ou independentes podem estabilizar a variância, normalizar a distribuição de probabilidade dos resíduos ou melhorar as relações lineares entre as variáveis. 
Fazendo uma alusão a indicadores econômicos, pode-se entender esse fenômeno como uma defasagem das variáveis no tempo. As variações que ocorrem em um ano podem exercer influência em anos posteriores, e isso pode ser estudado por intermédio de relações de causa e efeito quando determinadas as variáveis explicativas e a variável resposta.

Foram efetuados vários testes para escolha do melhor modelo: Hausman, Breusch-Pagan, Wooldridge e Wald.

A primeira das medidas estatísticas calculadas por intermédio da Regressão Linear Múltipla para o modelo hipotético é o $\mathrm{r}^{2}$, que, segundo Montgomery, Vining e Reck (2006), mede a proporção da variação em y (variável dependente ou resposta), que pode ser explicada pelas variáveis $\mathrm{x}$ (independentes ou explicativas) no modelo de regressão. $\mathrm{O} \mathrm{r}^{2}$ ajustado é uma medida de comparação entre modelos para se entender o ganho real quando se adiciona uma variável na análise.

\subsection{ANÁLISE DOS DADOS: IDEBINI (ANOS INICIAIS)}

As variáveis levantadas e definidas como variáveis explicativas para o modelo do IDEBINI são: Royalties Per Capita (x1) defasagem de um ano, IDEB(x2) anterior obtido e Meta(x3) cumprida para o ano analisado. Todas as variáveis foram testadas com informações de 2006 a 2013.

Foram efetuados cortes de valores com valor nulo para o IDEB anos iniciais e excluídas 88 observações, totalizando uma amostra para análise do IDEB dos anos iniciais ( $4^{\mathrm{a}}$ série ou $5^{\circ}$ ano) de 536 observações em 67 munícipios (unidades), sendo excluídos 11 deles (Alegre, Brejetuba, Divino de São Lourenço, Domingos Martins, Governador Lindenberg, Laranja da Terra, Presidente Kennedy, Santa Leopoldina, São Domingos do Norte, São Roque do Canaã e Vila Valério). Alguns destes possuem excelentes repasses de royalties do petróleo, como o caso de Presidente Kennedy, que em oito anos recebeu grandes cifras, sendo uma das cidades mais beneficiadas, alcançando o primeiro lugar no ranking de repasse de royalties, porém, nenhum deles possui nota em determinado período da pesquisa, comprometendo os resultados.

Tabela 1 - Medidas descritivas para IDEBINI e variáveis independentes

\begin{tabular}{llllllll}
\hline Variáveis & Média & Desvio padrão & Mín & $1^{\circ} \mathrm{q}$ & $2^{\circ} \mathrm{q}$ & $3^{\circ} \mathrm{q}$ & Max \\
\hline RoyalPerCapita & 104,93 & 342,71 & 0,13 & 13,37 & 32,83 & 89,21 & $5.539,54$ \\
lnRoyalPerCapita & 3,46 & 1,54 & $-2,04$ & 2,59 & 3,49 & 4,49 & 8,62 \\
IDEBINI & 4,75 & 0,68 & 2,90 & 4,30 & 4,70 & 5,20 & 7,00 \\
IDEBINI_A & 4,57 & 0,68 & 2,90 & 4,10 & 4,60 & 5,00 & 7,00 \\
\hline
\end{tabular}

Fonte: os autores. 
Observe que, de um total de 67 municípios com informações de IDEB anos iniciais e repasse de royalties, cerca de $75 \%$ deles possuem renda per capita dos royalties acima ou igual a $\mathrm{R} \$ 89,21$, em 50\% deles, os valores estão entre R\$ 32,83 e $\mathrm{R} \$ 89,21$, e $25 \%$ dos municípios têm renda per capita dos royalties abaixo ou igual a $\mathrm{R} \$ 13,37$.

Em relação à matriz de correlação para IDEB anos iniciais e variáveis independentes, a Tabela 2 demonstra que algumas variáveis são correlacionadas positivamente entre si.

Tabela 2 - Coeficientes de correlação para IDEBINI e variáveis independentes

\begin{tabular}{lrrrr}
\hline \multicolumn{1}{c}{ Variáveis } & \multicolumn{1}{c}{ IDEBINI } & InRoyaPercapita & IDEBINI_A & IDEBINI_M \\
\hline IdebIni & 1.0000 & & & \\
InRoyalPercapita & 0.4491 & 1.0000 & & \\
IDEBINI_A & 0.8624 & 0.4338 & 1.0000 & \\
IDEBINI_M & 0.1002 & -0.1738 & -0.0035 & 1.0000 \\
\hline
\end{tabular}

Fonte: os autores.

Foi efetuado o teste de multicolinearidade, sendo o VIF apresentado na Tabela 3 a seguir:

Tabela 3 - VIF IDEBINI

\begin{tabular}{lll}
\hline Variáveis & VIF & $1 /$ VIF \\
\hline lnRoyalPercapita & 1.28 & 0.782120 \\
IDEBINI_A & 1.24 & 0.806484 \\
IDEBINI_M & 1.04 & 0.963402 \\
Mean VIF & 1.19 & \\
\hline
\end{tabular}

Fonte: os autores.

O VIF com valor superior a 10 indicará multicolinearidade, porém, na análise dos resultados, estes apresentam VIF=1,19, ou seja, não existe presença de multicolinearidade entre as variáveis dependentes. Pela estatística do teste de Hausman, tem-se que o modelo de efeitos fixos é melhor que o de efeitos aleatórios, probabilidade chi (2) $=0.000$.

A Tabela 4 demonstra o modelo de efeitos fixos, e a Tabela 5, o modelo de efeitos aleatórios. 
No teste de Chow, a estatística do teste F da linha inferior da estimativa de efeitos fixos, bem como seu respectivo p-valor indicam que o modelo de efeitos fixos é melhor que o pool, com valor de $\mathrm{F}(66,466)=3.11$ e Prob $>\mathrm{F}=0.0000$.

Tabela 4 - Efeitos fixos - IDEB anos iniciais e variáveis independentes

\begin{tabular}{lllll}
\hline Variáveis & Coef. & Erro padrão & Estatística t & Probabilidade \\
\hline lnRoyalPerCapita & 0.2198338 & 0.0161175 & 13.64 & 0.000 \\
IDEBINI_A & 0.4298984 & 0.0346847 & 12.39 & 0.000 \\
IDEBINI_M & 0.4141557 & 0.0572339 & 7.24 & 0.000 \\
Constante & 1.643108 & 0.1331823 & 12.34 & 0.000 \\
$\mathrm{R}^{2}:$ & Estatística F: & & Probabilidade F: \\
0.6064 & 415.69 & & 0.0000 & \\
& Observações: & & Total de grupos: \\
& 536 & & 67 & \\
\hline
\end{tabular}

Fonte: os autores.

Os diferentes valores de $\mathrm{R}^{2}$ indicam como o modelo se ajusta, $\mathrm{R}^{2}=0,6064$, em geral, o modelo de efeitos fixos é explicado em 60,64\%.

O teste $\mathrm{F}$ na última linha é utilizado para verificar se o modelo pool é mais adequado que o modelo de efeitos fixos. Ou seja, as variáveis independentes conseguem explicar a variação no índice de educação dos anos iniciais ( $4^{\mathrm{a}}$ série e $5^{\circ}$ ano) analisado. A equação em relação ao modelo de efeitos fixos para IDEB anos iniciais fica da seguinte maneira:

$$
1,64=\hat{a}_{0}+\hat{a}_{1} 0,22+\hat{a}_{2} 0,43+\hat{a}_{3} 0,41+\stackrel{\circ}{i}_{i}
$$

Tabela 5 - Efeitos aleatórios - IDEB anos iniciais e variáveis independentes

\begin{tabular}{lllll}
\hline Variáveis & Coeficientes & Erro Padrão & Estatística Z & Probabilidade \\
\hline lnRoyalPerCapita & 0.0523022 & 0.0104727 & 4.99 & 0.000 \\
IDEBINI_A & 0.8064721 & 0.0232401 & 34.70 & 0.000 \\
IDEBINI_M & 0.3000807 & 0.0519151 & 5.78 & 0.000 \\
Constante & 0.6051993 & 0.1072661 & 5.64 & 0.000 \\
R2: & Estatística Wald: & & Probabilidade Wald: \\
0.7654 & 1735.90 & & 0.0000 & \\
& Observações: & & Total de grupos: & \\
& 536 & & 67 & \\
\hline
\end{tabular}

Fonte: os autores. 
Para IDEB anos iniciais, no modelo de efeitos aleatórios tem-se $\mathrm{R}^{2}=0,7654$, em geral, o modelo de efeitos aleatórios é explicado em 76,54\%. O modelo, nesse caso, é o seguinte:

$$
0,60=\hat{a}_{0}+\hat{a}_{1} 0,052+\hat{a}_{2} 0,81+\hat{a}_{3} 0,30+\stackrel{\circ}{a}_{i}
$$

O teste para verificar a ocorrência da homocedasticidade foi efetuado com base no teste de Breusch-Pagan, no qual o resultado indica que efeitos aleatórios não são preferíveis ao modelo pool (Prob>chi(2)=1.0000), sem a presença de heterocedasticidade, portanto, os modelos não foram estimados com erro. Rejeita-se a hipótese nula de ausência de autocorrelação (Prob>F=0.0000) para o teste de Wooldridge.

No teste de Wald rejeita-se a hipótese nula de ausência de heterocedasticidade (Prob $>$ chi2 $=0.0000$ ), valor do teste Wald=698.42. O modelo escolhido para análise foi o de efeitos fixos ( $f e$ ), conforme apresentado no teste de Hausman.

As análises estatísticas aqui desenvolvidas, materializadas com diversos testes de robustez, demonstraram que, estatisticamente, nos municípios capixabas, à medida que se aumentam os royalties per capita de petróleo e gás, após aplicados controles, existe uma tendência ao aumento no indicador do IDEB nos anos iniciais.

\subsection{ANÁLISE DOS DADOS: IDEBFIN (ANOS FINAIS)}

Da mesma forma que foi analisado o IDEBINI, as variáveis levantadas e definidas como variáveis explicativas para o modelo do IDEBFIN são: Royalties Per Capta (x1) defasagem de um ano, IDEB(x2) anterior obtido e Meta(x3) cumprida para o ano analisado. Todas as variáveis foram testadas com informações de 2006 a 2013, para efeito de se investigarem os impactos nos índices de educação.

Para o tratamento de dados no painel, foram feitos cortes para os anos finais (IdebFin) da mesma forma que se fez para os anos iniciais. Os municípios sem valores do IDEB anos finais foram excluídos, reduzindo a amostra para análise do IDEB dos anos finais ( $8^{\mathrm{a}}$ série ou $9^{\circ}$ ano) para 384 observações em 48 municípios (unidades). Foram excluídos 30 municípios (Água Doce do Norte, Águia Branca, Alegre, Alto Rio Novo, Atílio Vivacqua, Barra de São Francisco, Brejetuba, Divino de São Lourenço, Dores do Rio Preto, Ecoporanga, Governador Lindenberg, Ibiraçu, Ibitirama, Irupi, Itaguaçu, Itapemirim, Jaguaré, Jerônimo Monteiro, Marechal Floriano, Marilândia, Muniz Freire, Muqui, Ponto 
Belo, Presidente Kennedy, Rio Novo do Sul, Santa Leopoldina, Santa Maria de Jetibá, São Domingos do Norte, São José do Calçado e São Roque do Canaã).

O corte para efeito de análise do IDEB anos finais foi de 30 municípios, contra 11 do IDEB anos iniciais. A cidade de Presidente Kennedy mais uma vez figura na listagem e está em primeiro lugar no ranking de repasse de royalties, totalizando os oito anos.

Foram excluídos do modelo os dados referentes às cidades que não apresentaram no banco de dados o índice IDEB anos finais ( $8^{a}$ série ou $9^{\circ}$ ano). O banco de dados inicial contava com 78 municípios, mas para ajuste do modelo, as informações de 30 municípios foram desconsideradas. A base final contém, exatamente, os dados históricos de 48 municípios.

Para a modelagem, todos os dados foram logaritmizados da variável RoyalPerCapita em razão da alta variabilidade encontrada, que pode ser medida pelo desvio padrão.

A estatística do teste de Hausman para o IDEB anos finais não é definida positivamente; Sant’anna (2006) afirma: “O teste de Hausman é usado para testar a compatibilidade dos dados quanto aos efeitos fixos ou aleatórios dado a semelhança dos resultados não foram aqui utilizados”, sendo apresentados os resultados de efeito fixos e aleatórios.

Um teste mais formal pode ser realizado, o Teste de Hausman, baseado nas diferenças das estimativas de efeitos fixos e aleatórios. Pela estatística do teste de Hausman, tem-se que o modelo de efeitos fixos é melhor que o de efeitos aleatórios, probabilidade chi $(2)=0.000$.

Para compreensão do problema em estudo, foram utilizadas algumas medidas descritivas, adicionando a variável RoyalperCapita para efeitos de demonstração e a variável independente transformada InRoyalperCapita, bem como a variável dependente e as demais variáveis independentes, considerando o período de 2006 a 2013, conforme Tabela 6.

Tabela 6 - Medidas descritivas para IDEBFIN e variáveis independentes

\begin{tabular}{llllllll}
\hline Variáveis & Média & Desvio padrão & MÍN & $1^{\circ} \mathrm{Q}$ & $2^{\circ} \mathrm{Q}$ & $3^{\circ} \mathrm{Q}$ & $\mathrm{MAX}$ \\
\hline RoyalPercapita & 384.01 & 88,55 & 213,71 & 0,13 & 11,44 & 29,36 & 79,28 \\
lnRoyalPerCapita & 384.02 & 3,32 & 1,57 & $-2,04$ & 2,44 & 3,38 & 4,37 \\
IDEBFIN & 384.03 & 4.025521 & 0.5645532 & 2.50 & 3.60 & 4.00 & 4.40 \\
IDEBFIN_A & 384.04 & 3.976562 & 0.5500749 & 2.50 & 3.60 & 4.00 & 4.30 \\
\hline
\end{tabular}

Fonte: os autores.

Observe que, de um total de 48 municípios com informações de IDEB anos finais e repasse de royalties, 75\% deles possuem renda per capita dos royalties acima 
ou igual a R\$ 29,36, em 50\% deles, os valores estão entre R\$ 11,44 e R\$ 29,36, e 25\% dos municípios têm renda per capita dos royalties abaixo ou igual a R\$ 0,13.

A matriz de correlação para IDEB anos finais e variáveis independentes (Tabela 7), demonstra que algumas variáveis são correlacionadas positivamente entre si.

Tabela 7 - Coeficientes de correlação para IDEBINI e variáveis independentes

\begin{tabular}{lllll}
\hline & IDEBFIN & InRoyalperCapita & IDEBFIN_A & IDEBFIN_M \\
\hline IDEBFIN & 1.0000 & & & \\
InRoyalPerCapita & 0.2100 & 1.0000 & & \\
IDEBFIN_A & 0.8151 & 0.2460 & 1.0000 & \\
IDEBFIN_M & 0.0752 & -0.3375 & -0.2027 & 1.0000 \\
\hline
\end{tabular}

Fonte: os autores.

O VIF com valor superior a 10 indicará multicolinearidade, porém, na análise dos resultados, estes apresentam VIF=1,13, ou seja, não existe presença de multicolinearidade. apontou multicolinearidade aceitável entre as variáveis dependentes.

Foi efetuado o teste de multicolinearidade, sendo o VIF conforme Tabela 8 a seguir:

Tabela 8 - VIF IDEBINI

\begin{tabular}{lll}
\hline Variáveis & VIF & 1/VIF \\
\hline lnRoyalPerCapita & 1.17 & 0.853188 \\
IDEBFIN_M & 1.15 & 0.870812 \\
IDEBFIN_A & 1.08 & 0.923311 \\
Mean VIF & 1.13 & \\
\hline
\end{tabular}

Fonte: os autores.

Na Tabela 9 apresenta-se o modelo de efeitos fixos, e na Tabela 10, o modelo de efeitos aleatórios. 
Tabela 9 - Efeitos fixos - IDEB anos finais e variáveis independentes

\begin{tabular}{lllll}
\hline Variáveis & Coeficientes & Erro padrão & Estatística t & Probabilidade \\
\hline lnRoyalPerCapita & 0.0879873 & 0.0143446 & 6.13 & 0.000 \\
IDEBFIN_A & 0.5252945 & 0.0503808 & 10.43 & 0.000 \\
IDEBFIN_M & 0.3010569 & 0.0371425 & 8.11 & 0.000 \\
Constante & 1.536799 & 0.1973152 & 7.79 & 0.000 \\
R2: & Estatística F: & & Probabilidade F: & \\
0.6732 & 67.61 & & 0.0000 & \\
& Observações: & & Total de grupos: & \\
& 384 & & 48 & \\
\hline
\end{tabular}

Fonte: os autores.

No teste de Chow, a estatística do teste F da linha inferior da estimativa de efeitos fixos, bem como seu respectivo p-valor indicam que o modelo de efeitos fixos é melhor que o pool, com valor $\mathrm{F}(47,333)=1.80$ e Prob $>\mathrm{F}=0.0017$.

Esses coeficientes implicam dizer que a cada aumento de uma unidade na variável x (explicativa), a variável y (resposta) é aumentada ou diminuída do valor representado pelo coeficiente de inclinação da reta de regressão $(\beta)$ quando os demais se mantêm constantes.

O modelo de efeitos fixos para IDEBFIN ficará da seguinte maneira:

$$
1,54=\hat{a}_{0}+\hat{a}_{1} 0,088+\hat{a}_{2} 0,53+\hat{a}_{3} 0,30+\stackrel{\circ}{a}_{i}
$$

Tabela 10 - Efeitos aleatórios - IDEB anos finais e variáveis independentes

\begin{tabular}{lllll}
\hline Variáveis & Coeficientes & Erro Padrão & Estatística Z & Probabilidade \\
\hline InRoyalPerCapita & 0.0344388 & 0.0103316 & 3.33 & 0.001 \\
IDEBFIN_A & 0.8705695 & 0.0283354 & 30.72 & 0.000 \\
IDEBFIN_M & 0.3290012 & 0.0334595 & 9.83 & 0.000 \\
Constante & 0.3318031 & 0.1155528 & 2.87 & 0.004 \\
R2: & Estatística Wald: & & Probabilidade Wald: \\
0.7326 & 1040.88 & & 0.0000 & \\
& Observações: & & Total de grupos: \\
& 384 & & 48 & \\
\hline
\end{tabular}

Fonte: os autores.

Foi encontrado o valor para $r^{2}=67,32 \%$ no modelo de efeitos fixos e $r^{2}=73,26 \%$ no modelo de efeitos aleatórios. Ou seja, as variáveis independentes conseguem expli- 
car nos dois modelos a variação no índice de educação dos anos finais ( $8^{\mathrm{a}}$ série e $9^{\circ}$ ano) analisado. O modelo de efeitos aleatórios para IDEBFIN ficará da seguinte maneira:

$$
0,33=\hat{a}_{0}+\hat{a}_{1} 0,034+\hat{a}_{2} 0,87+\hat{a}_{3} 0,33+\stackrel{\circ}{a}_{i}
$$

No teste de Breusch-Pagan, o resultado indica que efeitos aleatórios não são preferíveis ao modelo pool (Prob>chi(2)=1.0000), sem a presença de heterocedasticidade, portanto, os modelos não foram estimados com erro padrão.

Rejeita-se a hipótese nula de ausência de autocorrelação para o teste de WooldridgeProb $>F=0.0000$. No teste de Wald, rejeita-se a hipótese nula de ausência de heterocedasticidade (Prob>chi2=0.0000), valor do teste Wald=3074.22.

As análises estatísticas aplicadas para o IDEB anos finais, materializadas com diversos teste de robustez, de modo semelhante àquele para o IDEB anos iniciais, evidenciam que, estatisticamente, nos municípios capixabas, à medida que se aumentam os royalties per capita de petróleo e gás, após aplicados controles, existe uma tendência ao aumento no indicador do IDEB nos anos finais.

Os resultados reforçam o argumento de que o aumento de royalties per capita traz como consequência direta um aumento aparente na qualidade educacional básica de determinado município. Nesta pesquisa não se propôs a explicar o grau da eficiência desses recursos adicionais, mas esboça o efeito marginal positivo que desempenham sobre o IDEB, seja dos anos iniciais seja dos anos finais.

\section{CONSIDERAÇÕES FINAIS}

Uma pesquisa sobre os impactos das receitas advindas de royalties do petróleo e gás na qualidade da educação básica, além de propósitos descritivos, é de extrema importância para a tomada de decisões e formulação de políticas públicas de investimentos em educação, definindo estratégias e programa de governo, bem como fontes de financiamento.

$\mathrm{Na}$ pesquisa quantitativa realizada ficou evidenciado que o crescimento do Índice de Desenvolvimento da Educação Básica (IDEB) dos anos iniciais e finais nos municípios do Espírito Santo está relacionado com as receitas de transferências de royalties do petróleo e gás natural. Em suma, documentou-se, entre os anos 2006 e 2013, uma associação positiva dos royalties per capita com o crescimento do IDEB. 
É necessário que os governos federais, estaduais e municipais, durante as discussões da transferência dos recursos do pré-sal, apresentem e defendam que os investimentos sejam feitos em educação, principalmente, na sua base, o Ensino Fundamental, que forma cidadãos para toda uma vida.

Com a aprovação da Lei dos Royalties no Congresso Nacional, pode-se indicar uma mudança de paradigma e uma melhor distribuição desses valores para todos os municípios brasileiros, além daqueles diretamente atingidos pela exploração. As discussões e regulamentações propõem uma distribuição de 75\% dos recursos para a educação e de 25\% para a saúde, conforme Lei dos Royalties (n. 12.858/2013).

Como os investimentos dos recursos dos royalties do pré-sal somente terão efeitos em alguns anos, segue a proposta de que este estudo seja replicado novamente após um período de recursos arrecadados com o pré-sal, comparando-se os resultados do antes e do depois no que se refere a como estão os índices da educação básica dos municípios.

As limitações desta pesquisa estão relacionadas à restrição e confiabilidade dos dados obtidos. Ainda que a proposta tenha sido o estudo concentrado apenas em um estado da Federação, reconhece-se que o escopo poderia ser ampliado por uma análise de todos eles, particularmente daqueles que onde os municípios são beneficiários dos royaties. Outro ponto que suscita dúvida seria daqueles municípios nos quais não foi possível obter informações, o receio natural é que a ausência ou a não disponibilidade pública desses dados esteja relacionado por variáveis não controladas neste estudo, o que poderia implicar um erro de mensuração.

Com a meta prevista de 6,0 para o IDEB em 2022, também pode ser interessante repetir os testes dos índices de educação básica dos anos iniciais e finais em um período posterior. Acrescente-se, por pertinente, que alguns municípios ficaram sem participar da análise em razão da falta de informações do IDEB, bem como muitos municípios que recebem altos valores de royalties ficaram fora dos testes estatísticos por não terem participado e figurado nos resultados do INEP/MEC.

Almeja-se que futuras pesquisas assegurem uma coleta de 100\% dos 78 municípios, ou, talvez, possam expandir para incluir municípios dos estados do Rio de Janeiro e Bahia, assim como incluir novas variáveis de controle. Registre-se que nesse cenário futuro já se antecipa que os royalties decorrentes do pré-sal poderão ser incorporados na análise. 


\section{REFERÊNCIAS}

BARBOSA, D. H. Guia dos royalties do petróleo e do gás natural. Rio de Janeiro: Agência Nacional do Petróleo, 2001. 156 p. Disponível em: <www.anp.gov.br>. Acesso em: 15 nov. 2009.

BRASIL. Constituição da República Federativa do Brasil. 38. ed. São Paulo: Saraiva, 2008.

BRASIL. Decreto n. 1, de 07 de fevereiro de 1991. Regulamenta o pagamento da compensação financeira instituída pela Lei n. 7.990, de 28 de dezembro de 1989, e dá outras providências. JusBrasil, 14 jan. 1991. Disponível em: <http://presrepublica.jusbrasil.com.br/legislacao/110841/decreto-1-91>. Acesso em: 27 fev. 2015.

BRASIL. Lei n. 7.990, de 28 de dezembro de 1989. Institui, para os Estados, Distrito Federal e Municípios, compensação financeira pelo resultado da exploração de petróleo ou gás natural, de recursos hídricos para fins de geração de energia elétrica, de recursos minerais em seus respectivos territórios, plataformas continental, mar territorial ou zona econômica exclusiva, e dá outras providências. Diário Oficial da União, Brasília, DF, 29 dez. 1989. Disponível em: <http://www.planalto.gov.br/ccivil_03/leis/17990.htm>. Acesso em: 28 fev. 2015.

BRASIL. Lei n. 9.478, de 06 de agosto de 1997. Dispõe sobre a política energética nacional, as atividades relativas ao monopólio do petróleo, institui o Conselho Nacional de Política Energética e a Agência Nacional do Petróleo e dá outras providências. Diário Oficial da União, Brasília, DF, 07 ago. 1997. Disponível em: <http:// www.planalto.gov.br/ccivil_03/leis/19478.htm>. Acesso em: 28 fev. 2015.

BRASIL. Lei n. 12.858, de 09 de setembro de 2013. Dispõe sobre a destinação para as áreas de educação e saúde de parcela da participação no resultado ou da compensação financeira pela exploração de petróleo e gás natural, com a finalidade de cumprimento da meta prevista no inciso VI do caput do art. 214 e no art. 196 da Constituição Federal; altera a Lei n. 7.990, de 28 de dezembro de 1989; e dá outras providências. Diário Oficial da União, Brasília, DF, 10 set. 2013. Disponível em: <http://www.planalto.gov.br/ccivil_03/_Ato2011-2014/2013/Lei/L12858.htm>. Acesso em: 20 nov. 2013.

BRASIL. Ministério da Fazenda. Secretaria do Tesouro Nacional. Receitas Públicas: manual de procedimentos. Brasília, DF: STN/Coordenação-Geral de Contabilidade, 2007. 233 p. 
COSTA, C. C. R. C. da. O IDEB como indicador da qualidade da educação brasileira: o caso da região sudeste. Revista e-Exacta, Belo Horizonte, v. 3, n. 2, 2010. Disponível em: <http://revistas.unibh.br/index.php/dcet/article/view/297> . Acesso em: 20 dez. 2014.

CROZATTI, J.; ALMEIDA, L. T. de. A qualidade do gasto público com o ensino fundamental nas escolas municipais. In: ENCONTRO NACIONAL DA ASSOCIAÇÃO NACIONAL DE PÓS-GRADUAÇÃO E PESQUISA EM ADMINISTRAÇÃO, 36., 2012. Rio de Janeiro. Anais... Rio de Janeiro, 2012.

GIAMBIAGI, F.; ALÉM, A. C. Finanças públicas: teoria e prática no Brasil. 3. ed. Rio de Janeiro: Campus, 2008.

GONÇALVES, A. S. et al. Os impactos sócio-econômicos da arrecadação e aplicação dos royalties nos municípios de Carmópolis e Pirambú - SE. In: CONFERÊNCIA NACIONAL DE POLÍTICAS PÚBLICAS CONTRA A POBREZA E A DESIGUALDADE, 1., 2010, Natal. Anais... Natal: Universidade Federal do Rio Grande do Norte, 2010. Disponível em: <http://www.cchla.ufrn.br/cnpp/pgs/ anais/Arquivos\%20GTS\%20-\%20recebidos\%20em\%20PDF/Os\%20Impactos\%20 S\%C3\%B3cio-econ\%C3\%B4micos\%20da\%20Arrecada\%C3\%A7\%C3\%A3o\%20 e\%20Aplica\%C3\%A7\%C3\%A3o\%20dos\%20Royalties\%20nos\%20Munic\%C3\%ADpios\%20de\%20Carm\%C3\%B3polis\%20e\%20Piramb\%C3\%BA\%20 -\%20SE.pdf>. Acesso em: 10 nov. 2014.

HAIR JÚNIOR, J. F. et al. Análise multivariada de dados. 6. ed. Porto Alegre: Bookman, 2009.

INSTITUTO NACIONAL DE ESTUDOS E PESQUISAS EDUCACIONAIS ANÍSIO TEIXEIRA. Ideb 2013 indica melhora no ensino fundamental. Brasília, DF. Disponível em: <http://portal.inep.gov.br/web/portal-ideb/portal-ideb>. Acesso em: 17 out. 2014.

LEVINE, D. M.; BERENSON, M. L.; STEPHAN, D. Estatística: Teoria e Aplicações. Rio de Janeiro: LTC, 2008.

LEVINE, D. M. et al. Estatística: teoria e aplicação - Usando o Microsoft Excel em português. Rio de Janeiro: LTC, 2005. 
LOPES, J. E. F.; PASSADOR, C. S.; PASSADOR; J. L. A Federação e a Educação Básica no Brasil: a Descentralização em Cheque? In: ENCONTRO NACIONAL DA ASSOCIAÇÃO NACIONAL DE PÓS-GRADUAÇÃO E PESQUISA EM ADMINISTRAÇÃO, 38., 2014, Rio de Janeiro. Anais... Rio de Janeiro, 2014.

MACHADO JÚNIOR, T. J.; REIS, H. da C. A Lei 4.320 comentada. 31. ed. rev. e atual. Rio de Janeiro: IBAM, 2002.

MACHADO JÚNIOR, T. J.; REIS, H. da C. A Lei 4.320 comentada. 32. ed. rev. e atual. Rio de Janeiro: IBAM, 2008.

MALHOTRA, K. N. Pesquisa de marketing: uma orientação aplicada. 3. ed. Porto Alegre: Bookman, 2001.

MINISTÉRIO DA FAZENDA. Secretaria do Tesouro Nacional. Manual técnico de contabilidade aplicada ao setor público - volume 2 - Manual de Despesa Nacional. 1. ed. 2008.

MINISTÉRIO DO PLANEJAMENTO E ORÇAMENTO. Portaria n. 42, de 14 de abril de 1999. Atualiza a discriminação da despesa por funções de que tratam o inciso I, do $\S 1^{\circ}$, do art. $2^{\circ}$, e $\S 2^{\circ}$, do art. $8^{\circ}$, ambos da Lei $n^{\circ} 4.320$, de 17 de março de 1964; estabelece conceitos de função, subfunção, programa, projeto, atividade, operações especiais e dá outras providências. 15 abr. 1999. Disponível em: <http:// www3.tesouro.gov.br/legislacao/download/contabilidade/portaria42.pdf $>$. Acesso em: 27 fev. 2015.

MONTGOMERY, D. C.; VINING, G. G.; PECK, E. Introduction to linear regression analysis. 4th ed. New York: John Wiley \& Sons, 2006.

MUSGRAVE, R. A. Teoria das finanças públicas. São Paulo: Atlas, 1973.

MUSGRAVE, R. A. The theory of public finance: a study in public economy. Southern Economic Journal, v. 26, i. 3, p. 234-238, Jan. 1960.

MUSGRAVE, R. A.; MUSGRAVE, P. Finanças Públicas - Teoria e Prática. Rio de Janeiro: Campus, 1980.

PINDYCK, R. S.; RUBINFELD, D. L. Microeconomia. 6. ed. São Paulo: Prentice Hall, 2004. 
SILVA, C. M. D. da et al. Eficiência na Alocação de Recursos Públicos na Educação Básica em Minas Gerais. In: ENCONTRO NACIONAL DA ASSOCIAÇÃO NACIONAL DE PÓS-GRADUAÇÃO E PESQUISA EM ADMINISTRAÇÃO, 37., 2013, Rio de Janeiro. Anais... Rio de Janeiro, 2013.

SILVA, C. C. da; SILVEIRA, S. de F. R. Análise do estágio de desenvolvimento socioeconômico dos principais municípios que recebem royalties de mineração do estado de Minas Gerais. In: ENCONTRO NACIONAL DA ASSOCIAÇÃO NACIONAL DE PÓS-GRADUAÇÃO E PESQUISA EM ADMINISTRAÇÃO, 36., 2012, Rio de Janeiro, Anais... Rio de Janeiro, 2012.

SPIEGEL, M. R. Probabilidade e Estatística. Makron Books: São Paulo, 1978.

RIBEIRO, E. Impacto dos Royalties do Petróleo no PIB Per Capita dos Municípios do Estado do Espírito Santo, Brasil. Dissertação (Mestrado em Ciências Contábeis - Programa de Pós-Graduação em Ciências Contábeis)-Fundação Instituto Capixaba de Pesquisa em Contabilidade, Economia e Finanças, Vitória, 2008.

RIBEIRO, E.; TEIXEIRA, A.; GUTIERREZ, C. E. C. Impacto dos royalties do petróleo no PIB per capita dos municípios do estado do Espírito Santo, Brasil. Revista Brasileira de Gestão de Negócios, São Paulo, v. 12, n. 34, p. 25-41, jan./mar. 2010.

SANT'ANNA, J. M. B. Efeito do gasto público sobre o PIB: um teste empírico nos municípios do estado do Espírito Santo. Dissertação (Mestrado em Ciências Contábeis - Programa de Pós-Graduação em Ciências Contábeis)-Fundação Instituto Capixaba de Pesquisa em Contabilidade, Economia e Finanças, Vitória, 2006.

SANT’ANNA, J. M. B. O impacto das ações estratégicas dos governos estaduais no nível do produto interno bruto. Dissertação (Mestrado em Administração Programa de Pós-Graduação em Administração)-Fundação Instituto Capixaba de Pesquisa em Contabilidade, Economia e Finanças, Vitória, 2011.

SENADO FEDERAL. Royalties. 2014. Disponível em: <http://www.senado.gov.br/ noticias/agencia/infos/inforoyalties_.htm>. Acesso em: 30 jan. 2015. 
Como citar este artigo:

\section{ABNT}

MARTINEZ, Antonio Lopo; REIS, Sério dos Santos. Impacto dos Royalties do Petróleo no índice de Educação Básica: análise do caso dos municípios capixabas.

RACE, Revista de Administração, Contabilidade e Economia, Joaçaba: Ed. Unoesc, v. 15, n. 2, p. 505-530, maio./ago. 2015. Disponível em: <http://editora.unoesc. edu.br/index.php/race>. Acesso em: dia/mês/ano.

\section{APA}

Martinez, A. L. \& Reis, S. dos S. (2016). Impacto dos Royalties do Petróleo no índice de Educação Básica: análise do caso dos municípios capixabas. RACE, Revista de Administração, Contabilidade e Economia, 15(2), 505-530. Recuperado de http://editora.unoesc.edu.br/index.php/race 
